Research article

\title{
The velocity of ultrasound in human primary melanoma tissue - implications for the clinical use of high resolution sonography Michael Weichenthal ${ }^{* 1}$, Peter Mohr ${ }^{2}$ and Eckard W Breitbart ${ }^{2}$
}

\author{
Address: ${ }^{1}$ Department of Dermatology, St.Georg Hospital, Lohmuhlenstr.5, D-20099 Hamburg, Germany and ${ }^{2}$ Department of Dermatology, \\ Buxtehude Hospital, Buxtehude, Germany \\ E-mail: Michael Weichenthal* - weichenthal@uke.uni-hamburg.de; Peter Mohr - MohrPe@csi.com; \\ Eckard W Breitbart - dermatologie@ hospit.std.shuttle.de \\ *Corresponding author
}

Published: 28 June 2001

Received: 16 April 200I

BMC Dermatology 200I, I:I

Accepted: 28 June 2001

This article is available from: http://www.biomedcentral.com//47I-5945/I/I

(c) 200I Weichenthal et al, licensee BioMed Central Ltd.

\begin{abstract}
Background: Ultrasonography with $20 \mathrm{MHz}$ frequency can be used to estimate tumour thickness preoperatively in malignant melanoma (MM) of the skin. The vertical invasion depth is the single most important prognostic factor for localised MM, and its preoperative knowledge would be very useful for the planning of surgical procedures. Since ultrasonographic distance measurements directly depend upon the tissue specific ultrasound velocity, we determined the ultrasound velocity in primary melanoma.
\end{abstract}

Results: Ultrasound velocity was calculated from runtime differences of a $20 \mathrm{MHz}$ ultrasound signal along a known distance either through water alone or through thick specimens of primary MM. The ultrasound velocities varied between $1553 \mathrm{~m} / \mathrm{s}$ and $1588 \mathrm{~m} / \mathrm{s}$ with a mean of I $564 \mathrm{~m} / \mathrm{s}$ in four different MM specimens. The analysis of different parts of the specimens showed that the variation of the calculated velocities was larger between different specimens than within one individual specimen.

Conclusions: The ultrasound velocity in MM tissue may be slightly lower than normally assumed, thereby explaining a part of the overestimation usually found in sonographic measurement of melanoma invasion depth. Additionally, the variation of ultrasound velocity between individual tumours may contribute to the impairment of the correlation found between sonometry and Breslow's measurement of MM invasion depth. For practical reasons, a setting of $1580 \mathrm{~m} / \mathrm{s}$ will be appropriate for ultrasonography of primary malignant melanoma.

\section{Introduction}

The tumour invasion depth according to Breslow [1] is the single most important prognostic factor in cutaneous malignant melanoma (MM) [2], and it is well established as the main determinant in recent staging systems for $\mathrm{cu}^{-}$ taneous MM. High resolution ultrasound imaging can be used for determination of melanoma invasion depth in vivo for preoperative staging purposes $[3,4]$. This may become especially useful for the planning of procedures like sentinel lymph node dissection (SLND), which is mostly performed in melanomas of more than $1.0 \mathrm{~mm}$ invasion depth.

Although the correlation between sonographical and histological measurements is high, it is subject to inaccuracies and several sources of error $[5,6]$. Sonometric 
measurement of MM invasion depth in vivo generally reveals somewhat higher values than histometric measurement $[3,5,7]$. Various factors including shrinkage of the fixed tissue [8] and misclassification of subtumoral inflammatory cells as part of the tumour [4] have been made responsible for this effect.

The validity of ultrasonographic distance measurements in vivo is basically depending on assumptions about the velocity of the ultrasound signal in the tissue under determination. Most studies of ultrasonographic measurements in MM assume a general velocity of $1580 \mathrm{~m} / \mathrm{s}$ based on data for whole human skin, although ultrasound velocity significantly varies in different tissues [9] and even in human skin of different sites [10] (Table 1).

Table I: Ultrasound velocity in different human tissues

\begin{tabular}{lccc}
\hline Tissue & $\begin{array}{c}\text { Frequency } \\
{[\mathrm{MHz}]}\end{array}$ & $\begin{array}{c}\text { velocity } \\
{[\mathrm{m} / \mathrm{s}]}\end{array}$ & $\begin{array}{c}\text { Temp } \\
{\left[{ }^{\circ} \mathrm{C}\right]}\end{array}$ \\
\hline Skin & & & \\
Breast & 10.0 & 1642 & 27 \\
Face & 10.0 & 1570 & 27 \\
Fat & 2.0 & 1476 & 35 \\
Blood & 7.5 & 1586 & 37 \\
Liver & 10.0 & 1608 & 37 \\
Bone & 0.1 & 3375 & 37 \\
& & & \\
\hline
\end{tabular}

Adapted from Goss et al. [9] and Escoffier et al. [10]

We investigated the ultrasound velocity in human melanoma tissue, since its overestimation would be an alternative explanation for measurement bias in sonometric measurement of MM invasion depth.

\section{Materials and methods}

Biopsy material of four patients with very large primary melanomas was used in order to obtain enough tissue for experimental measurements but still preserve enough of the specimen for routine histological evaluation. The specimen was processed immediately after surgery, cleaned from all subtumoral or subcutaneous tissue and placed in $0.7 \%$ saline.

Ultrasonographic measurements were performed using a DBR300 ultrasound device (Sonometrics Inc., New York, NY, USA) equipped with a highly damped $20 \mathrm{MHz}$ transducer.

Ultrasound velocity was calculated by measuring signal runtimes along a constant distance $\left(\mathrm{s}_{\mathrm{O}}\right)$ of $12.0 \mathrm{~mm}$ between the transducer and a plane plexiglas bottom either through water alone or with the melanoma specimen placed onto the plexiglas (Fig. 1). The runtimes were calculated using electronic cursors placed on the appropriate flanks of the scope signal. If to is the time for the signal to pass the distance so through water alone, $t_{M}$ the time to pass the tissue distance $\left(S_{M}\right)$, and $t_{w}$ the time to pass the remaining water distance $\left(\mathrm{s}_{\mathrm{W}}\right)$, then the velocity of the signal propagation in melanoma tissue can be calculated as:

$\mathrm{V}_{\mathrm{M}}=\mathrm{V}_{\mathrm{w}}\left(\mathrm{t}_{\mathrm{O}}-\mathrm{t}_{\mathrm{w}}\right) / \mathrm{t}_{\mathrm{M}}$

with the ultrasound velocity in water $\mathrm{v}_{\mathrm{w}}$ given as $1496 \mathrm{~m} /$ $\mathrm{S}$ at $25^{\circ} \mathrm{C}$.[11] For theoretical reasons, the maximal resolution of the runtime measurement of a $20 \mathrm{MHz}$ signal is about $0.05 \mu s$. Technical reasons, i.e. the steepness of the signal flanks, lead to additional inaccuracies. With tenfold measurements of the empty system a standardised coefficient of variance of about 0.42 percent was reached (data not shown).

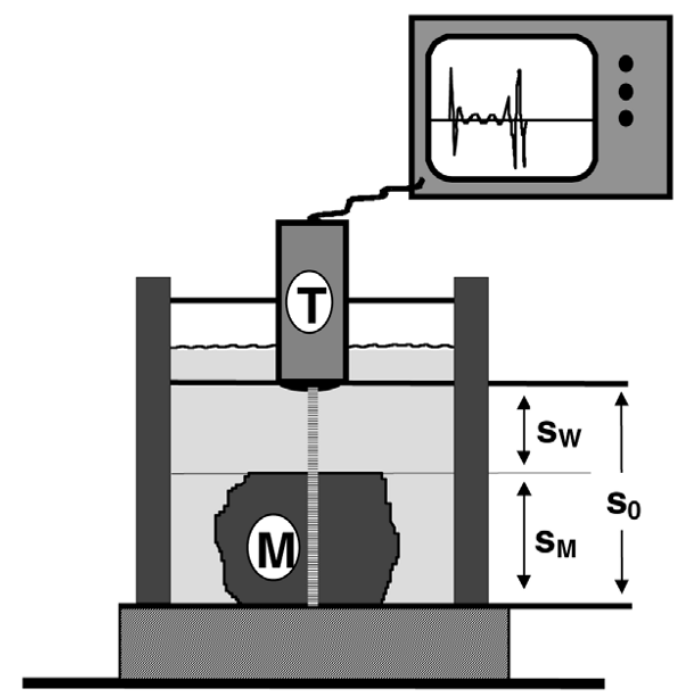

Figure I

Schematic representation of the sonographic device. A $20-\mathrm{MHz}$ transducer $(\mathrm{T})$ is fixed to a basin filled with water. The 12-millimeter-distance (so) between the transducer and the plexiglas bottom can be measured with or without interposing tissue samples. The melanoma tissue (M) can be fixed onto the bottom with a flexible clip in different positions.

Depending on the available amount of tissue, measurements were performed repeatedly at different sites of the specimen. Mean values were calculated from tenfold measurements and compared between the different specimens using simple analysis of variance. The results 


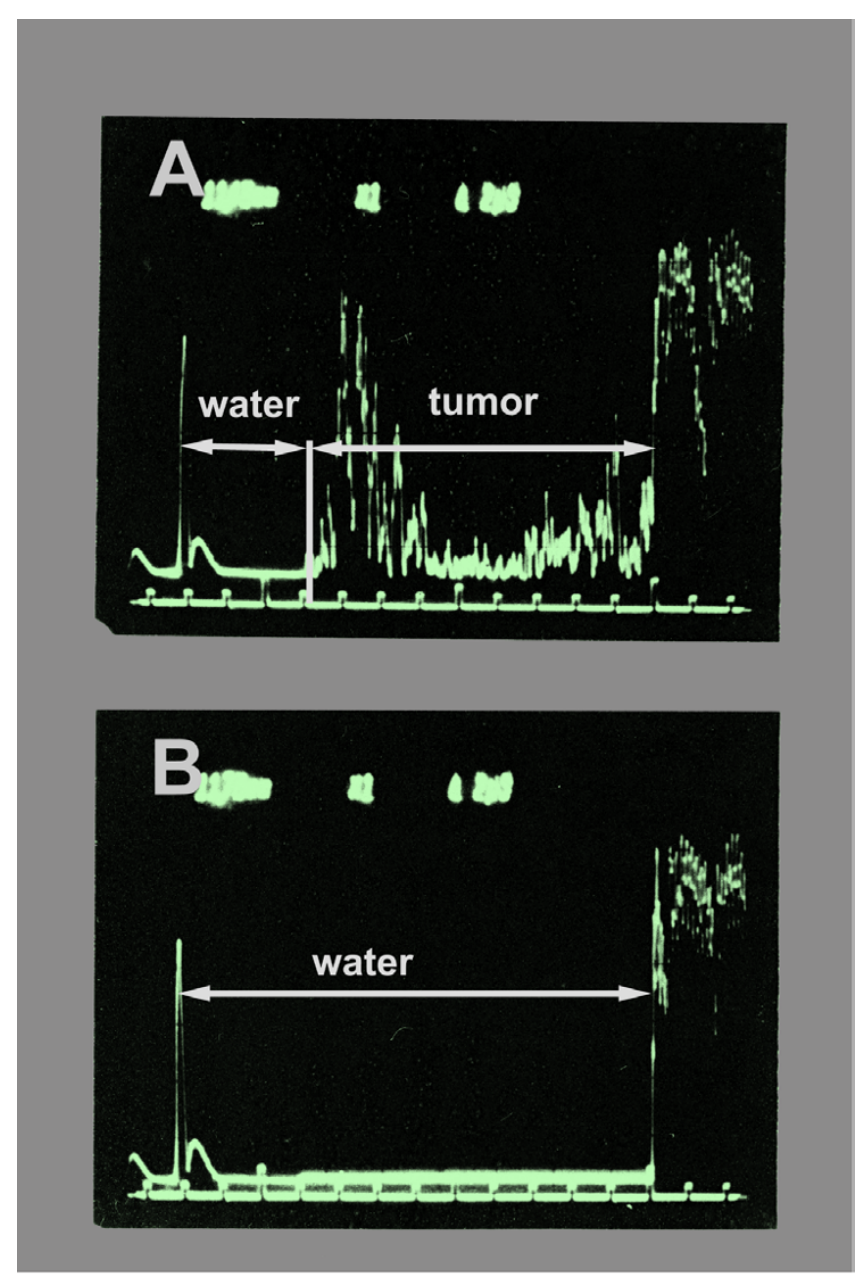

Figure 2

Scope signals of the measurements. The signal runtimes were determined by electronic cursors. The time the ultrasound pulse needs to pass a given distance changes whether the melanoma tissue (tumour) is interposed $(A)$ or whether it goes through water alone (B). From the runtime difference with or without the tissue sample in the signal way, the ultrasound velocity within the tissue can be calculated.

were applied to a set of 402 melanoma patients using simple regression analysis of log-normalised values of Breslow's and sonographic invasion depth measurements. All calculations were done with a statistical software package (SPSS 5.0, SPSS Inc, Chicago, IL).

\section{Results}

Of the four tissue specimens, two were large enough to perform measurements in six different parts of the material. The two other melanomas were measured in two points each. As shown in Table 2, the samples gave varying results with calculated velocities around the expected region of $1580 \mathrm{~m} / \mathrm{s}$, ranging from $1553 \mathrm{~m} / \mathrm{s}$ to $1588 \mathrm{~m} / \mathrm{s}$, and the calculated mean was $1564 \mathrm{~m} / \mathrm{s}$. Although the in- tra-tumoral variation was considerably high, analysis of variance revealed significant differences between the four different tumours $(F=4.53 ; p=0.02)$. Specifically, the tumours number 3 and number 4 showed ultrasound velocities slightly higher than $1580 \mathrm{~m} / \mathrm{s}$, while the very large tumours (No.1 and 2) gave significantly lower values (Fig. 2).

Table 2: Ultrasound velocities in primary melanomas

\begin{tabular}{lcccc}
\hline Lesion & Localisation & $\begin{array}{c}\text { Invasion } \\
\text { depth } \\
\text { (Breslow) } \\
{[\mathrm{mm}]}\end{array}$ & $\begin{array}{c}\text { number of } \\
\text { sites } \\
\text { per speci- } \\
\text { men }\end{array}$ & $\begin{array}{c}\text { velocity } \pm \text { SEM } \\
{[\mathrm{m} / \mathrm{s}]}\end{array}$ \\
\hline & & & \\
1 & cheek & 12.0 & 6 & $1553 \pm 17.9$ \\
3 & shoulder & 7.2 & 6 & $1561 \pm 6.0$ \\
4 & leg & 2.6 & 2 & $1588 \pm 20.9$ \\
& leg & 6.8 & 2 & $1585 \pm 14.9$ \\
\hline
\end{tabular}

In order to illustrate the impact of the findings for the accuracy and validity of clinical measurements, we applied a corrected tissue specific velocity to a historical set of clinical ultrasound measurements. These had been obtained from consecutive melanoma patients during the years 1983 to 1991 . Figure 4 shows a scatter plot of data from 400 patients with a log-scale representation of histo-metric against sonometric determination of tumour thickness originally using an ultrasound velocity of 1580 $\mathrm{m} / \mathrm{s}$. The values were recalculated using an assumption of $1564 \mathrm{~m} / \mathrm{s}$ as ultrasound velocity in melanoma tissue instead. In the raw data, the slope of the regression line (B) rose from 0.82 to 0.84 , still differing significantly from perfect correlation in which case B should equal 1.o. Accordingly, using log-transformed data the intersection with the ordinate (constant) rose from -0.28 to -0.26 only. Since this was a proportional operation, the measures of correlation were not affected.

\section{Discussion}

The recent proposal for a new staging system for malignant melanoma makes pathological staging of regional lymph nodes obligatory for all melanomas of more than 1.0 $\mathrm{mm}$ invasion depth [12]. Since most institutions have abandoned radical elective lymph node dissection for primary malignant melanoma, sentinel lymph node dissection (SLND) will be the preferred method for the assessment of the nodal status. SLND has been shown to give the most reliable results when the primary has not been removed at the time of lymphatic mapping. Therefore, preoperative determination of tumour thickness 


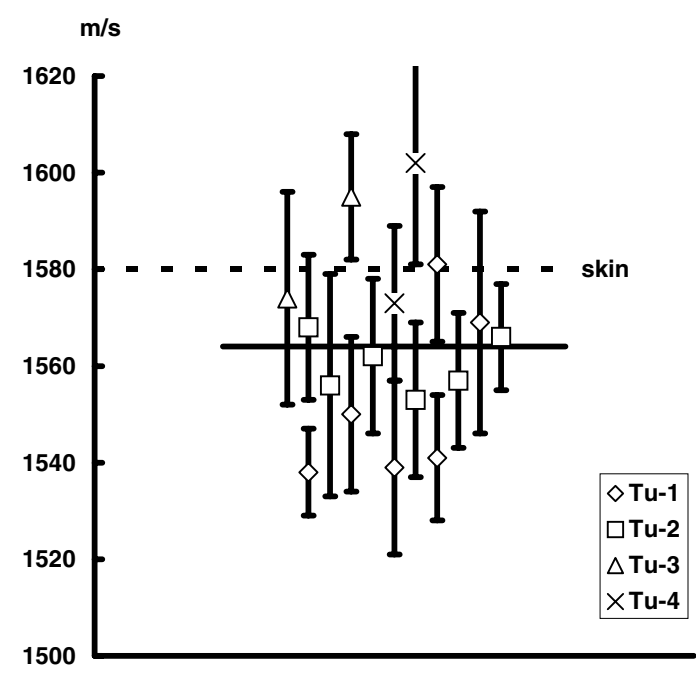

Figure 3

Calculated ultrasound velocities in different parts of 4 individual primary melanomas. The 16 measurements gave a mean value of $1564 \mathrm{~m} / \mathrm{s}$ (solid line). The dashed line represents the ultrasound velocity normally assumed in human skin $(1580 \mathrm{~m} / \mathrm{s})$.

using high resolution ultrasound would be of great value in the staging process of primary malignant melanoma.

Ultrasonographic measurements of melanoma invasion depth in vivo are usually made under the two assumptions. First, that ultrasound velocity in primary melanoma tissue equals that of normal skin. Second, that ultrasound velocity is constant in different individual tumours. As we could show, both assumptions can only partially be confirmed.

Although we investigated only material from 4 different tumour specimens, our measurements indicate that in some melanomas the ultrasound velocity may be lower than the commonly accepted value of $1580 \mathrm{~m} / \mathrm{s}$. As a consequence, the estimated distances will be biased towards greater values in these tumours. Since the ultrasound velocity in biological tissues depends on certain characteristics of the particular tissue, it is not surprising that the velocity varies between individual tumors and even between different sites of normal skin [10].

It is a consistent phenomenon that ultrasound derived estimates of melanoma invasion depth are statistically higher than the histological figures [5, 3, 7]. Several factors have been implied in the overestimation of tumour thickness including tissue shrinkage [8] during formalin fixation, or the presence of nevus cells or subtumoral in-

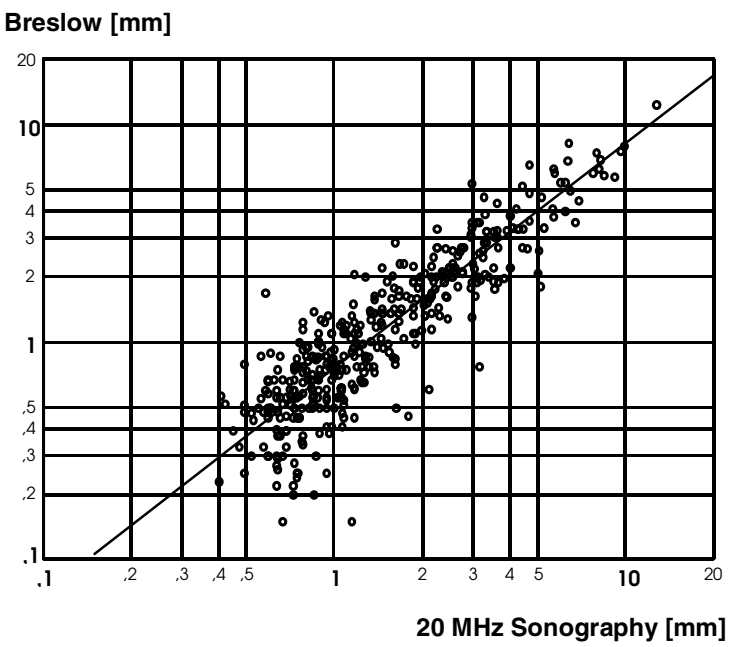

\section{Figure 4}

Correlation between sonometric and histometric measurement of tumour invasion depth in $\mathbf{4 0 0}$ patients with primary malignant melanoma. Simple regression analysis revealed a correlation coefficient $R=0.92$ $(p<0.000 \mathrm{I})$, while the slope of the regression line $(b=0.82)$ was substantially differing from perfect correlation between both measures, in which case b should equal I.0. As can be seen from the graph, sonometry was systematically overestimating tumour depth. After recalculation of the estimations using a different ultrasound velocity for melanoma tissue of $1564 \mathrm{~m} / \mathrm{s}$ instead, the value of slope only rose to $b=0.84$, which still accounted for a substantial overestimation compared to histological measurement.

flammatory cells, both of which cannot be distinguished from the melanoma sonographically [4]. In contrast to this, the loss of skin tension after excision of the tumour leads to an increase in tumour thickness, partly eliminating the effect of shrinkage during fixation of the tissue [8]. Histological measurement of tumour invasion depth underestimates the 'true' invasion depth when step sections have not been performed. In their study of melanoma specimens less than $0.75 \mathrm{~mm}$ thick, Solomon et al.[13] found the maximum tumour thickness to be 25 percent larger when serial sequences were investigated as compared to the routine processing method. Therefore, the overestimated tumour thickness values may also reflect the more precise detection of the thickest part of the tumour by real-time sonographic imaging.

While systematic overestimation is a statistical problem which can be compensated for by simple regression methods, accuracy is yet another problem in determining melanoma invasion depth sonographically. It has been correctly stated that even high correlation coefficients as given by several studies are not an appropriate measure of the usefulness of this method [5]. The 
strength of correlation between sonometry and histometry is influenced by different factors. First, all of the factors mentioned above not only have systematic influence but also contribute to the variation of sonometric or histometric measurements. Second, accuracy of both methods is limited. In histological measurement of invasion depth significant intra- and interobserver variation exists, revealing kappa statistics between only 0.49 and 0.76 among different pathologists $[14,15,16]$.

Corresponding data for sonographic measurements of melanomas are lacking, but based on studies of normal skin[17] and sonographic distance measurements in other clinical fields [18], a significant interobserver variability has to be assumed. Additionally, as we could show, the variances of ultrasound velocities between different tumours are significantly higher than variances within different parts of an individual tumour. This means that there are differences in ultrasound velocity among individual tumours. These differences constitute another source of error in sonographic distance measurements, although the relative amount of variation seems to be quite low.

In summary, we could demonstrate that overestimation of the ultrasound velocity in primary melanoma tissue may be an additional reason for measurement bias in the prediction of melanoma thickness by high resolution sonography. Furthermore, our data show that tissue specific differences of ultrasound velocity may be a source of error in ultrasound determination of melanoma invasion depth, but with a maximal difference of about 1.5 percent from the mean value, the impact of this type of error seems to be limited.

As we also illustrated, both the overestimation of the mean ultrasound velocity as well as its variation in different tissue specimens may only explain a small part of the deviation from histological measurements. For a better quantification of tumour specific variation of ultrasound velocity in malignant melanoma further investigations of larger samples are needed. For clinical purposes however, it will still be appropriate to use a setting of $1580 \mathrm{~m} / \mathrm{s}$ for the ultrasonography of human skin including the imaging of malignant melanoma. Based on these findings, the use of preoperative thickness measurement in malignant melanoma can be advocated, especially when the performance of SLND in dependence on tumor thickness is intended.

\section{Competing interests}

None declared

\section{References}

I. Breslow A: Thickness, cross-sectional areas and depth of invasion in the prognosis of cutaneous melanoma. Ann Surg 1970, I 72:902-8

2. Balch CM: Cutaneous melanoma: prognosis and treatment results worldwide. Semin Surg Oncol 1992, 8:400-14

3. Breitbart EW, Rehpenning W: Potentials and limits of ultrasonic diagnosis for the in vivo determination of the depth of invasion of malignant melanoma. Hautkr 1983, 58:975-87

4. Gassenmaier G, Kiesewetter F, Schell H, Zinner M: Value of high resolution ultrasound in determination of vertical tumor thickness in malignant melanoma of the skin. Hautarzt 1990, 4I:360-4

5. Tacke J, Haagen G, Hornstein OP, Huettinger G, Kiesewetter F, Schell H, Diepgen TL: Clinical relevance of sonometry-derived tumour thickness in malignant melanoma-a statistical analysis. $\mathrm{Br}$ J Dermatol 1995, I32:209-14

6. Partsch B, Binder M, Puspok-Schwarz M, Wolff $K$, Pehamberger $H$ : Limitations of high frequency ultrasound in determining the invasiveness of cutaneous malignant melanoma. Melanoma Res 1996, 6:395-8

7. Dummer W, Blaheta HJ, Bastian BC, Schenk T, Bröcker EB, Remy W: Preoperative characterization of pigmented skin lesions by epiluminescence microscopy and high-frequency ultrasound. Arch Dermatol 1995, I 31 1:279-85

8. Salmhofer W, Rieger E, Soyer HP, Smolle J, Kerl H: Influence of skin tension and formalin fixation on sonographic measurement of tumor thickness. J Am Acad Dermatol 1996, 34:34-9

9. Goss SA, Johnston RL, Dunn F: Compilation of empirical ultrasonic properties of mammalian tissues. J Acoust Soc 1980, 68:93108

10. Escoffier C, Querleux B, De Rigal J, et al: In vitro study of the velocity of ultrasound in the skin. Bioeng Skin 1986, 2:87-94

II. Del Gosso VA: Sound speed in pure water and sea water. J Acoust Soc Amer 1970, 47:947-9

12. Balch CM, Buzaid AC, Atkins MB, Cascinelli N, Coit DG, Fleming ID, Houghton A, Kirkwood JM, Mihm MF, Morton DL, Reintgen D, Ross MI, Sober A, Soong SJ, Thompson JA, Thompson JF, Gershenwald JE, McMasters KM: A new American Joint Committee on Cancer staging system for cutaneous melanoma. Cancer 2000, 88: $|484-9|$

13. Solomon AR, Ellis CN, Headington JT: An evaluation of vertical growth in thin superficial spreading melanomas by sequential serial microscopic sections. Cancer 1983, 52:2338-4I

14. Colloby PS, West KP, Fletcher A: Observer variation in the measurement of Breslow depth and dark's level in thin cutaneous malignant melanoma. J Pathol 1991, I 63:245-50

15. Corona R, Mele A, Amini M, De Rosa G, Coppola G, Piccardi P, Fucci $M$, Pasquini $P$, Faraggiana $T$ : Interobserver variability on the histopathologic diagnosis of cutaneous melanoma and other pigmented skin lesions. J Clin Oncol 1996, I4:12 I8-23

16. McDermott NC, Hayes DP, al-Sader MH, Hogan JM, Walsh CB, Kay $E W$, Leader MB: Identification of vertical growth phase in malignant melanoma. A study of interobserver agreement. Am J Clin Pathol 1998, I I 0:753-7

17. Tan CY, Statham B, Marks R, Payne PA: Skin thickness measurement by pulsed ultrasound: its reproducibility, validation and variability. $\mathrm{Br} J$ Dermatol 1982, I06:657-67

18. Wolman I, Jaffa AJ, Sagi J, Hartoov J, Amster R, David MP: Transvaginal ultrasonographic measurements of endometrial thickness: a reproducibility study. J Clin Ultrasound 1996, 24:35 I-4

\section{Pre-publication history}

The pre-publication history for this paper can be accessed here:

http://www.biomedcentral.com/content/backmatter/ 1471-5945-1-1-b1.pdf 